\title{
Challenges for Future Flexible Electric Power Systems
}

\author{
Ali Feliachi
}

\begin{abstract}
This paper describes some of the challenges that face the operation of future electric power systems. These systems are becoming more flexible and agile. Their physical structures and connections are continuously changing as microgrids, electric vehicles, and other generation and storage devices are connected/disconnected from the grid, which result in new challenges for the operation, management, and control of the systems of the future that incorporate active participation of the consumers, and high penetration of intermittent nature renewable resources such as wind and solar.
\end{abstract}

Keywords- Electric Power Systems, Renewable Energy, Smart Grids.

\section{NOMENCLATURE}

$\begin{array}{ll}\text { ACE } & \text { Area Control Error. } \\ \text { DG } & \text { Distributed Generator. } \\ \text { HVDC } & \text { High Voltage Direct Current. } \\ \text { ISO } & \text { Independent System Operator. } \\ \text { PCC } & \text { Point of Common Coupling. } \\ \text { PV } & \text { Photovoltaic. } \\ \text { US } & \text { United States of America }\end{array}$

\section{INTRODUCTION}

The objective of this paper is to describe some of the challenges that face the operation and control of flexible and agile power systems. Advances in power electronics, renewable, storage, computing, communication and sensor technologies and their declining cost will increase their proliferation in the power system to make it a system of systems. Decarbonization, digitization and decentralization are the main drivers behind the accelerated pace at which the system is evolving towards a system of systems. Electrification was recognized as the Greatest Engineering Achievement of the twentieth century [1] by the US National Academy of Engineering, (ahead of Automobile, Airplane, Water Supply and Distribution, Electronics, Radio and Television, Agricultural Mechanization, and Computers). Electricity is a key factor in determining the standard of living in the world. Fig.1. shows the 2018 ranking of some countries [2] (top 9 countries, Algeria and similar countries in terms of electricity consumption per capita in $\mathrm{kWh}$ ).

The resiliency of the aforementioned system will depend on how these subsystems are operated and managed taking advantages of the newest technologies. An agile and flexible system is defined here as an interconnection of many subsystems that can "come and go" based on contingencies due to weather, resource availability, malicious attacks, or fault conditions. It can be a single system, known as the grid, or it can collapse into several islanded microgrids, with the

Manuscript received February 16, 2021; revised March 16, 2021.

Ali Feliachi is with the Lane Department of Computer Science and Electrical Engineering, West Virginia University, Morgantown, WV 26506 (alfeliachi@mail.wvu.edu).

Digital Object Identifier (DOI): 10.53907/enpesj.v1i1.8

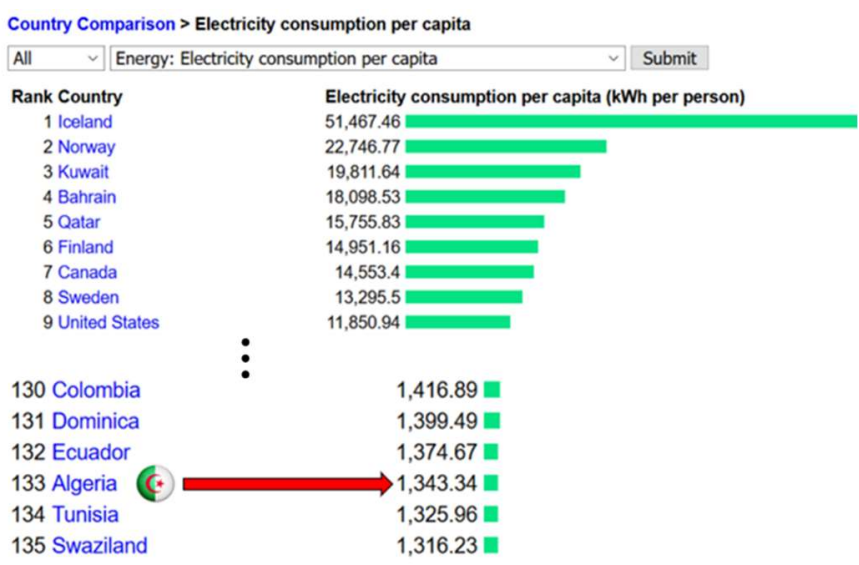

Fig. 1: Electricity Consumption per Capita (kWh per person) possibility of morphing back to a single system.

The wealth of information available due to the proliferation of sensors, if utilized properly and communicated efficiently, along with automated switching, could be the key to the control and operation of smart grids of the future. However, the transition from idea to practice has proven to be quite challenging. Successful implementation requires an intelligent control system with an adaptive communication layer as well as a robust and scalable information network. The realization of such a large-scale flexible network poses some key challenges, but if addressed judiciously will result in an autonomous, resilient, and efficient power system.

This paper is organized as follows. Section II presents a sketch of the flexible power system and a smart grid architecture. Section III defines renewable resources. Challenges are presented in section IV.

\section{FLeXIBLE POWER Systems AND SMART GRIDS}

A schematic of a flexible power system is shown in Fig. 1. A traditional power system is called the grid. Smart grids are defined as any additional subsystems that are added to the Grid through the Point of Common Coupling (PCC). Smart grid is loosely defined: it could be a Power Distribution Subsystem, a Consumer with storage and/or generation capabilities, etc.

A typical architecture of a Smart Grid is shown in Fig. 3. It consists of five layers. It first starts with a Power System with its physical power components and apparatusfollowed by the Communication layer which includes all the 


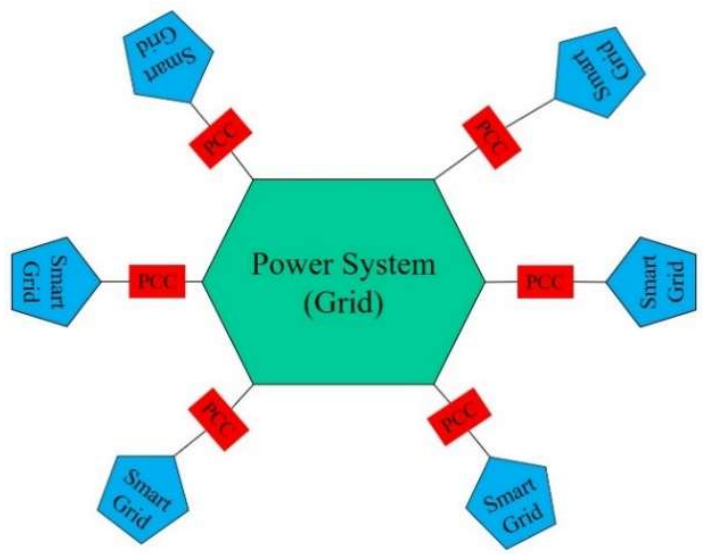

Fig. 2: Flexible Power System

communication devices and their protocols. The third is the Information layer that has the information flow, objects, and syntax. The fourth is the Function layer that describes the use cases, and has the supervisory control and data acquisition function, etc. The fifth is the Business layer that encompasses business cases, regulation, policies, etc. It is probably becoming necessary to add a sixth layer, a social layer, as social behavior and trends will affect this complex system.

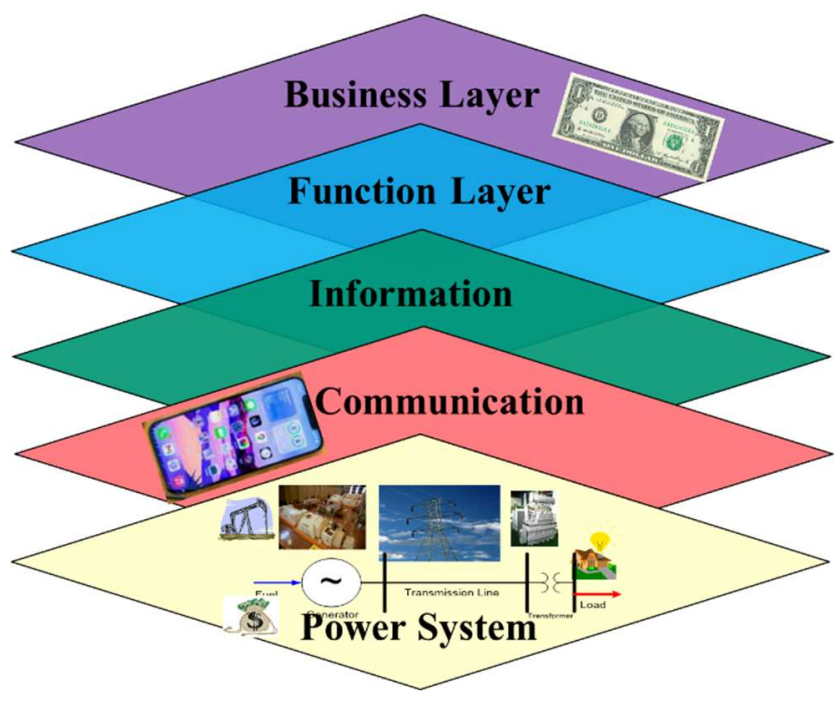

Fig. 3: Schematic of a Five-Layer Smart Grid Architecture

\section{RENEWABLE RESOURCES}

Renewable Energy is defined as the energy from sources that are naturally replenishing but flow limited. They are virtually inexhaustible in duration but limited in the amount of energy that is available per unit of time. The major types of Renewable Resources (shown in Fig. 4a and Fig. 4b) are:

- $\quad$ Biomass: (plants/animals)

- Wood and wood waste

- Municipal solid waste

- Landfill gas and biogas

- Ethanol

- Biodiesel

- Solar

- Wind

- Hydropower

- Geothermal (inside the earth)
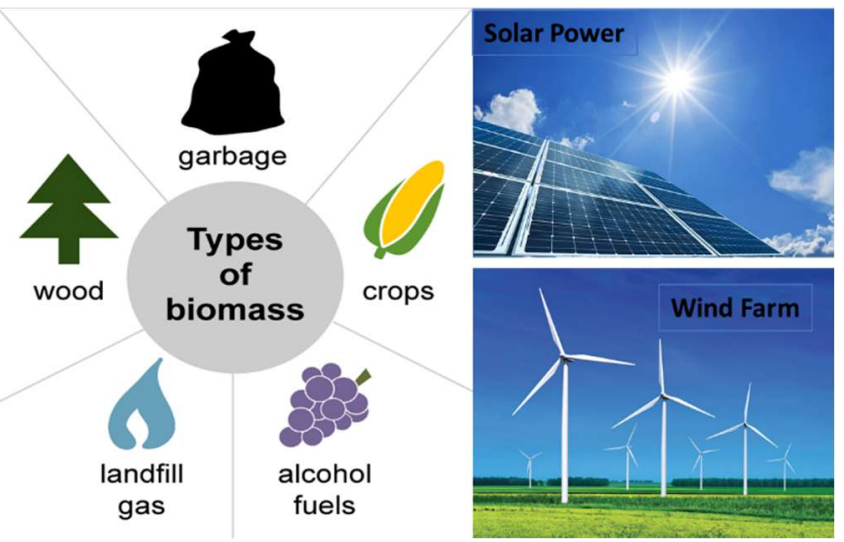

Fig. 4a: Renewable Energy Resources: Biomass, Solar and Wind
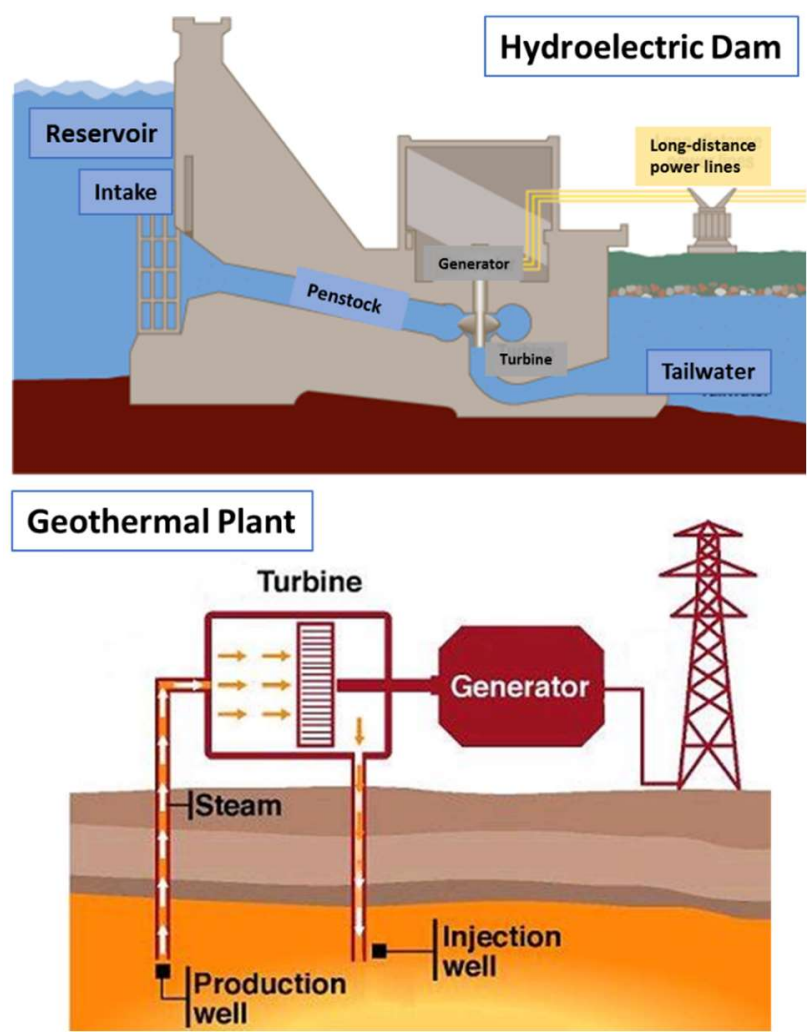

Fig. 4b: Renewable Energy Resources: Hydropower and Geothermal

These renewable resources are becoming a major challenge to traditional fossil fuel or nuclear units. Fig. 5. shows the US utility scale renewable generation in 2015 and 2019, especially in wind and solar, which are becoming a serious alternative to traditional fossil fuel generation.

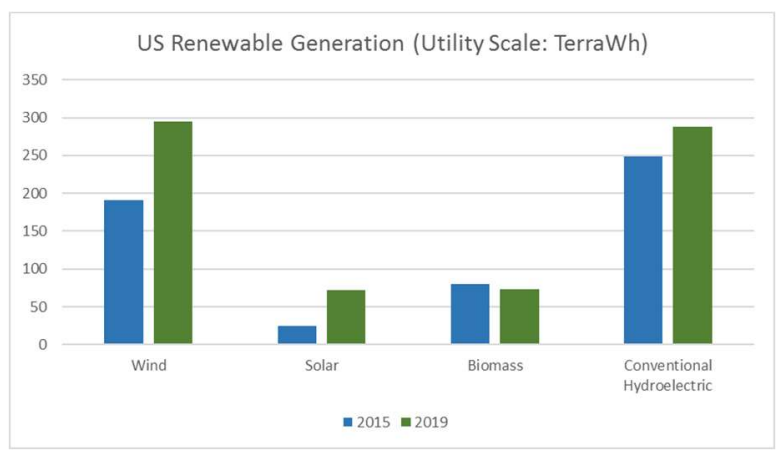

Fig. 5. US Renewable Generation in 2015 and 2019

The number of US PV installations is steadily increasing as shown in Fig. 6. This is due to government incentives and the decreasing cost of solar power which is now about $\$ 3$ per Watt 
installed [3]. The US has now surpassed two million solar installations [4].

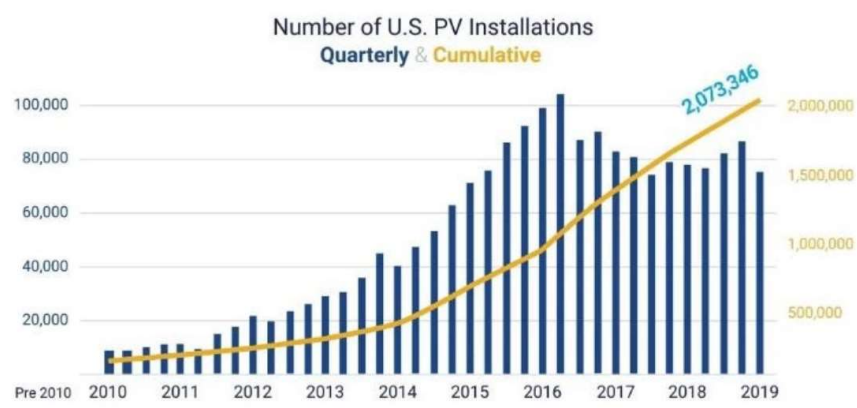

Fig. 6. Number of US PV Installations until 2019

\section{Challenges}

Challenges facing future power systems are many and they are due to the following factors that incorporate advances in technology, economics, but also social and policy considerations:

- Economics, Deregulation, Policy, Environment

- Multiple Infrastructures

- Electric Transportation

- Communication, Internet, Information

- Computation

- Data Analytics

- Cyber Security

- Operation

- Renewable Resources

○ Dispatch,

- Intermittent Resources

○ Network Constraints

- Units Ramp Up/Down: Duck Curve

- Control/Automation, Resiliency

- Power Electronics, Sensors

- Low Inertia, two-way power flow, switching

- Frequency/Voltage Control

\section{A. Economics, Policies and Environmental Challenges}

Economics, policies, and environmental issues play an important role in determining the penetration of renewable resources into the grid as well as the participation of different players in the generation and consumption of electricity. As an example, real time rates versus time of the day rates, versus fixed rates will affect consumer participation in demand response. Rooftop solar panels can become widespread if tax incentives are allowed. Electric vehicle owners can provide much needed storage to the grid if policies are in place to encourage it. Deregulation exists already in some form, but it is not common to all countries, or even amongst some states in the same country. These are challenging issues that will affect future power systems whose operation and resiliency depend on multiple market, social and engineering constraints.

A recent event in the state of Texas points to some real challenges that face the power grid. About 2 million homes in were left without electricity on Monday February 15, 2021 due to extreme winter conditions that witnessed a huge demand on the system, mainly for heating, and a diminishing supply. ERCOT, the Electric Reliability Council of Texas, the body that manages the grid, initiated rotating outages the night before to avoid a complete collapse of the system. Many factors seem to have contributed to this event (1) ERCOT is not connected to the other two big US systems, the Western and the Eastern systems, (2) the wind generation did not produce the expected output as some wind turbines froze, (3) the gas supply was not adequate due to the freezing weather and so some gas-fired power plants were not in service, (4) the market structure and the deregulation policies might have also contributed to the problem. Some blame the inexistence of a capacity market because ERCOT has only an energy market. Hence, producers are paid for the power they generate, and so, they do not invest for extra capacity. Deregulation resulted in the creation of new energy companies that promised consumers lower prices. Unfortunately, some customers who signed up with these retail energy companies have seen bills as high as $\$ 15,000$ for a month [5] instead of a bill in the $\$ 200$ range! For whatever reasons, a serious problem occurred, and challenges need to be addressed to avoid similar future incidents. For this problem alone the challenges encompass economics and market structures, deregulation and policies, environment as well as multiple infrastructures such as gas, and renewable which is the case of wind here.

\section{B. Multiple Infrastructure Challenges}

Some infrastructures have obvious effects on the power grid such as communication and information systems, hence the systems is referred to as a cyber-physical-system. But other infrastructures such as electric transportation, water, and gas are also important. In the event of Texas described in the previous section the lack of gas supply contributed to reduced production and aggravated the situation. During natural disasters, the loss of electricity has a profound effect on these other systems as most of the electric pumps for example cannot be used. Backup generation, which could represent as much as $15 \%$ of the total capacity in the US, is not used under normal conditions and if used judiciously could bring relief to the grid when the system is stressed.

In the following section, a scenario of an interaction between the grid operator and the electric transportation operator is presented. Fig. 7. is an illustration of this interaction. Each operator is responsible for unit commitments and scheduling of its own fleet. Such a problem can be optimized by exchanging price signals between the two infrastructures. Based on the load forecast, the grid operator commits generating units that can supply the load at minimum cost. The incremental cost or the price is provided to the electric fleet operator who schedules its charging and discharging electric vehicles and provides the information to the grid operator. Such an interaction could provide the most economical solution for both operators.

\section{Computation Challenges}

The system, being a dynamic cyber-physical-system with potentially a huge amount of data due to the huge number of devices and sensors, requires tools to analyze and determine the situation awareness of the "Internet of Power Things" [6]. Data Analytics and Machine Learning are fields that are well suited for applications in this area, but the challenges are its unique characteristics, as for example the dynamics of the system make the availability of data sets for training basically inexistent. This poses a computational challenge, and solving it requires specialized computational tools and algorithms.

Another challenge is to expand Smart Contracts based on technologies like blockchain to advance direct deals between diverse players such as electric vehicle riders and a fleet operator along with energy traders following the scheme 
depicted in Fig. 7. Blockchain has been used to link consumers and independent producers to buy and sell power. In New York City [7-8], as well as in Denmark, Blockchain is the technology adopted, and demonstrated, for rooftop solar energy trading by neighbors.

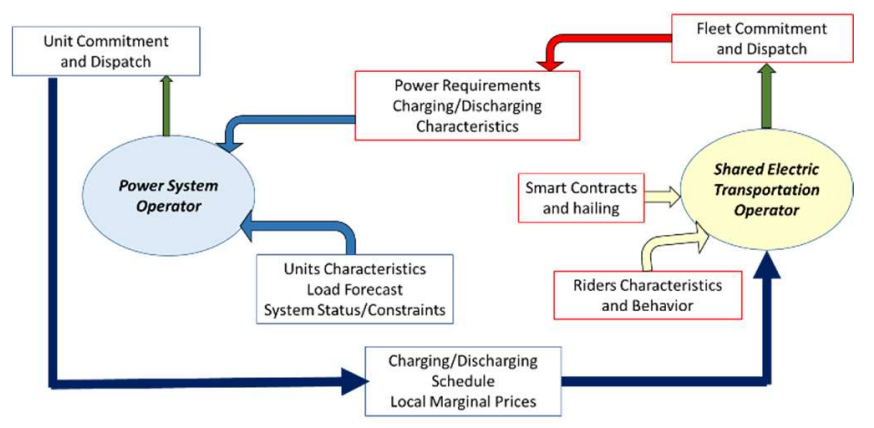

Fig. 7. Interaction Between Grid and Electric Fleet Operators

Finally, Cyber Security is a growing concern as daily attacks on the grid are becoming common. The Ukrainian example [9] of December 23, 2015, demonstrated that such attacks can happen. Hackers compromised information systems of three energy distribution companies in Ukraine and temporarily disrupted the electricity supply to consumers. It is the first known successful cyber attack on a power grid. Securing the system will remain a challenge as the grid becomes more flexible with a diverse number of players. This will increase the number of vulnerable points of attacks and will require novel cyber protection schemes.

\section{Operation Challenges}

\section{D1. Renewable Resources Challenges}

One of the challenges that result from the integration of renewable resources is their dispatchability; especially wind and solar resources; since their availability is intermittent even though their forecast is continuously improving.

Dispatchability of these renewable resources are summarized as follows:

- Dispatchable generators: those fueled by geothermal and biomass resources

- Non-dispatchable renewables: solar and wind energy. Dependent on the availability of naturally occurring resources.

- Hydroelectric generators fall between these categories; they can typically respond to dispatch signals, but they often have seasonal operational limitations that prevent them from being completely dispatchable.

Another challenge associated with renewable resources is their location. Wind farm for instance can be either offshore or at faraway sites, such as on top of mountains where strong winds are often recorded. In order to get the power into the load centers, re-enforcement or building new lines are required. HVDC is an option that many countries are evaluating to transport the power produced by these resources.

On June 12, 2007, the Las Angeles Times [10] newspaper reported that "California invested heavily in solar power. Now there's so much that other states are sometimes paid to take it. On 14 days during March, Arizona utilities got a gift from
California: free solar power. Well, actually better than free. California produced so much solar power on those days that it paid Arizona to take excess electricity its residents weren't using to avoid overloading its own power lines."

It is expected that Renewable Energy production will keep increasing as more countries are committed to this initiative. California has a mandatory $100 \%$ renewable electricity target for 2045 , as well as several other measures such as storage capacity and an expected burst of electric vehicles to combat pollution. California regulators approved a historic plan to mandate rooftop solar panels on most new single-family homes that will add about $\$ 9,500$ to the cost of building new houses. The solar mandate was expected to go into effect in 2020 .

\section{D2. Units Ramp Up/Down: Duck Curve}

From an operation point of view, incorporating these intermittent resources demands sharp ramping up and down of the traditional units, for example, during sunrise when solar power becomes available and before sunset when solar power is diminishing. The shape of the load curve has the form of a "duck," hence named 'duck curve' as shown in Fig. 8.

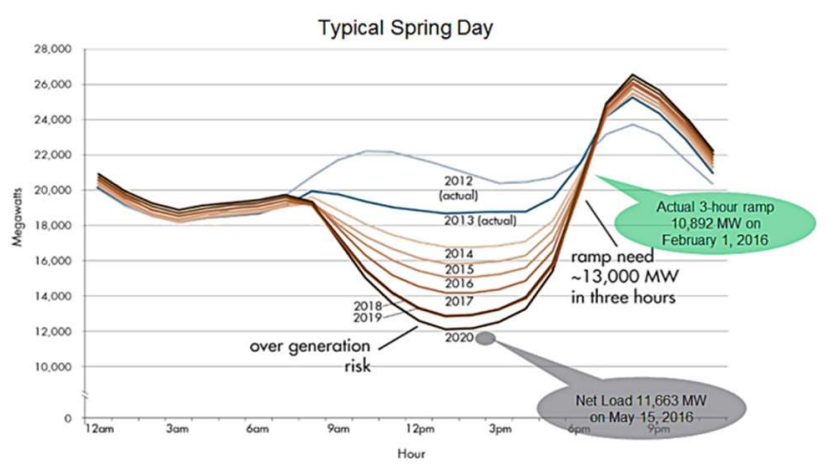

Fig. 8. Typical Duck Curve (California ISO)

Fig. 9. is an actual load curve from the California ISO (Independent System Operator) for the day of February 4, 2021 [11]. The green curve represents the load demand and the blue one is the electricity produced by the traditional units (net demand). The difference between the green and blue curves is the electricity produced by wind and solar generation. The average ramp-up in the afternoon for that day was very sharp, it was about $16 \mathrm{GW}$ in 3 hours.

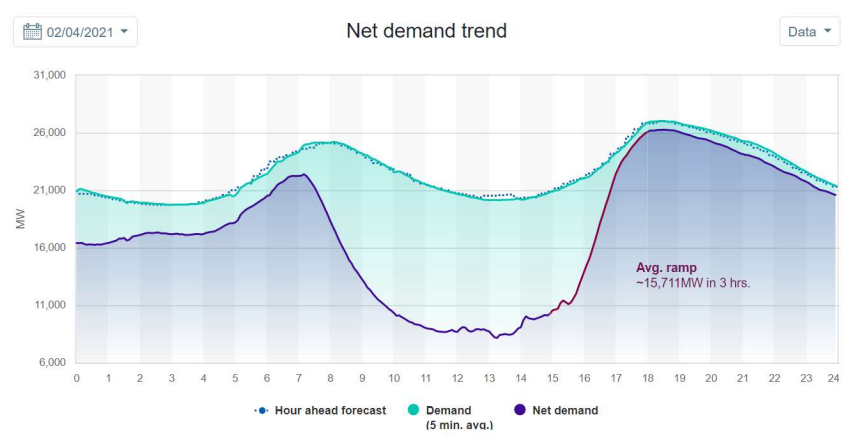

Fig. 9. California ISO Load Curve for February 4, 2021.

\section{E. Control Challenges}

The proliferation of renewable resources, which are mostly inverter-based generation, as shown in Fig. 10., results in lowinertia systems. This will affect several aspects of the control 
and management of the grid including stability, load frequency control and voltage control [12-17].

In this paper load frequency control and volage control challenges are discussed.

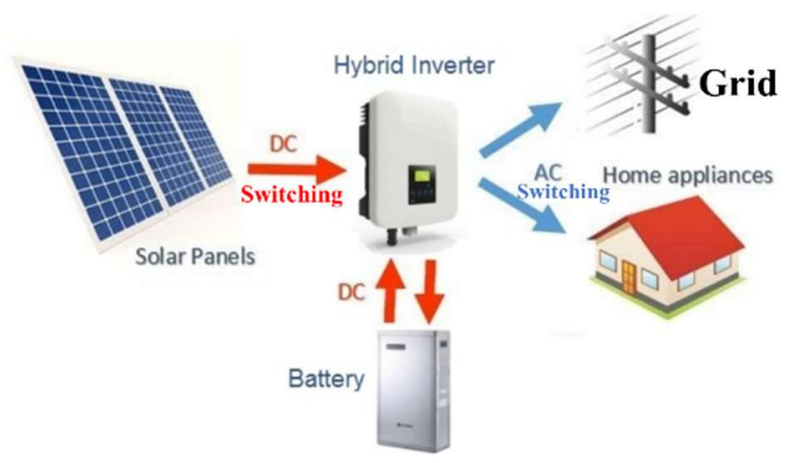

Fig. 10. Inverter Based Generation [18]

For the load frequency control problem illustration, the utilized system consists of two areas as shown in Fig. 11. The areas are called Red and Green Areas. These colors are utilized in the figures below using red for Area 1 and green for Area 2. Blue is used for the interchange power.

Two cases are analyzed. In Case 1, Area 1 has a large inertia and Area 2 has a small inertia. In Case 2, both areas have similar inertias. The scenario under study is the effect of a load increase in Area 1.

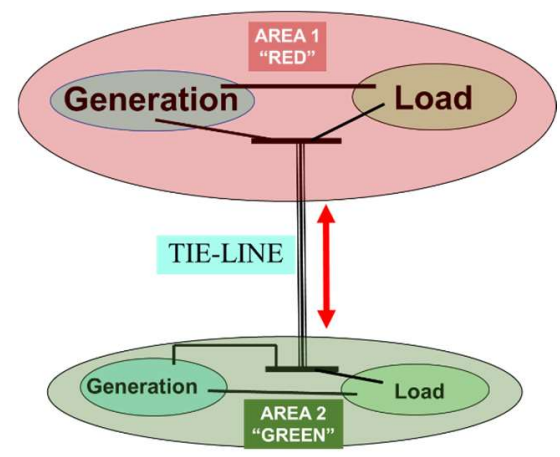

Fig. 11. A Two-Area Power System

An important quantity if the load frequency control problem is the Area Control Error (ACE). The statistics of ACE are a key to determining whether the areas are complying with the rules of operation so that the areas are helping each other during emergency, while each area is responsible for its own native load under normal conditions.

ACE for area (i) is defined as:

$$
A C E_{i}=\sum_{j} \Delta P_{i j}+\beta_{i} \Delta f_{i}
$$

Where $\Delta P_{i j}$ is the deviation from the nominal value of the power flow over the tie-line connecting area $i$ to area $j, \beta_{i}$ is a bias or the frequency characteristic of area $\mathrm{i}$, and $\Delta f_{i}$ is the deviation from the nominal value of the frequency in area $i$.

Simulations of the case studies described above are discussed here. Fig. 12a. shows that the frequency deviations in both areas are unstable, while Fig. 12b. shows that the frequency goes back to its nominal value for Case 2 .

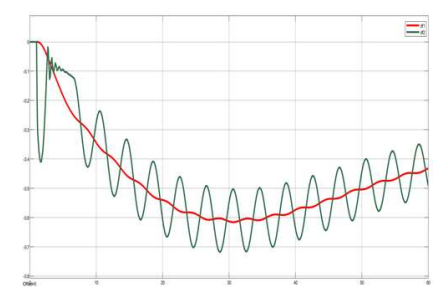

Fig. 12a. Frequency, Case 1

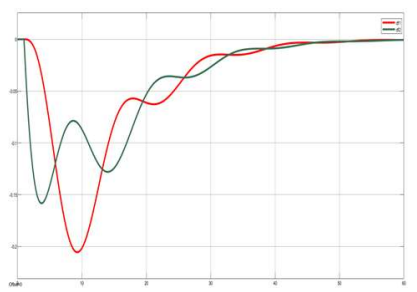

Fig. 12b. Frequency, Case 2
Fig. 13a. and Fig. 13b. show that the area control errors (ACE 1 and ACE 2) do not go back to zero as they are supposed to in Case 1, but they are converging, as required, in Case 2.

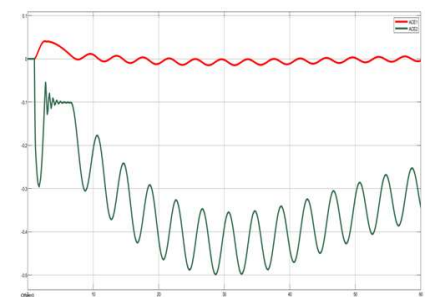

Fig. 13a. ACE, Case 1

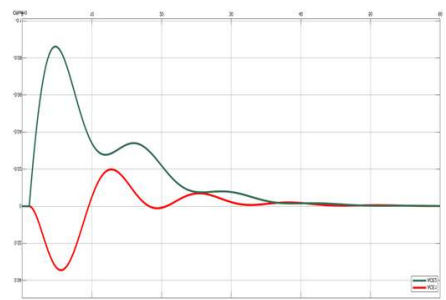

Fig. 13b. ACE, Case 2
Fig. 14a. shows that the power exchange between the areas, $\Delta P_{12}$ does not go back to its scheduled value, but Fig. 14b. shows that the system is behaving like it is supposed to.

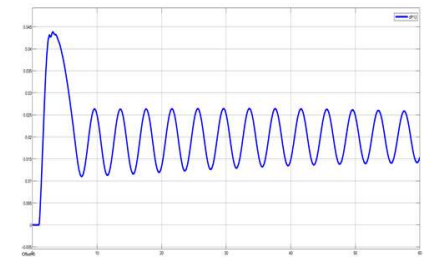

Fig. 14a. Tie-Line Power, Case 1

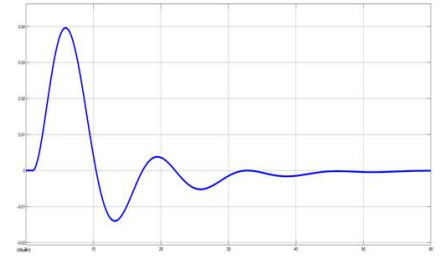

Fig. 14b. Tie-Line Power, Case 2
Finally, the change in mechanical power output is supposed to go to zero at steady state for area 2, which does not have a change in its demand. But Area 1 is supposed to increase its output to account for the increase of its load. Fig. 15a. and Fig. 15b. demonstrate that the results are as expected when both areas have similar sizes (Case 2), but when one area is larger than the other, in this case area 1 , the results are not as expected. The challenge then is to reconsider the expectations when different size or inertia systems are interconnected. Traditional measures and expectations for the area frequency and control areas statistics need to be revisited, challenging the existing compliance performance measures.

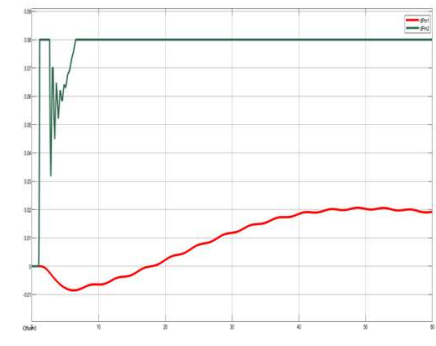

Fig. 15a. Mechanical Power Case 1

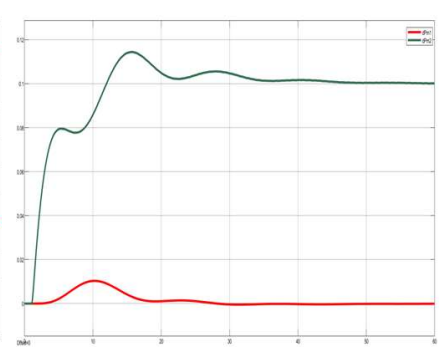

Fig. 15b. Mechanical Power Case 2
The last challenge presented in this paper is the voltage control in the presence of Distributed Generators (DGs). The DGs are mostly inverter-based generators dispersed throughout the microgrid. Therefore, the challenge addressed is to design practical distributed secondary voltage control. Because of advances in communication, one solution is to use/exploit this 
infrastructure as illustrated using the system shown in Fig. 16. [19].

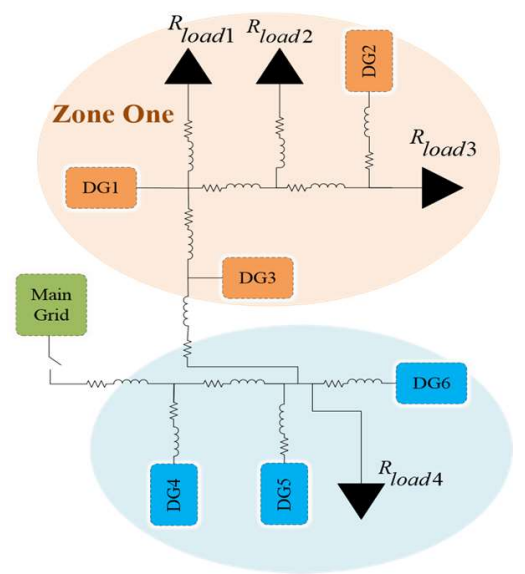

Fig. 16. A Six-DG-Two-Zone Microgrid

This problem has been solved using a consensus approach. Consensus algorithm is a distributed algorithm that can reach an agreement by sharing each node's voltage with its neighbors. A distributed cooperative tracking algorithm is proposed in [19]. In this algorithm, one of the DGs is selected as a leader node. This DG knows the reference value which will be communicated to the other DGs via a communication graph. The follower DGs will take that value and readjust their voltage controller set-points. All DGs must be connected to the leader via a connected graph. This algorithm works better in systems with DGs in close proximity. Instead of using the global consensus algorithm [19], the author and his colleagues have proposed a distributed or zonal consensus alternative [20].

The wireless communication network is shown in Fig. 17a. for the global consensus and in Fig. 17b. for the zonal consensus.

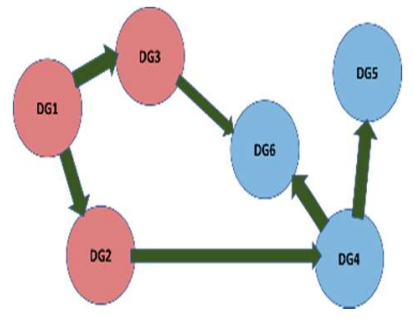

Fig. 17a. Global Consensus
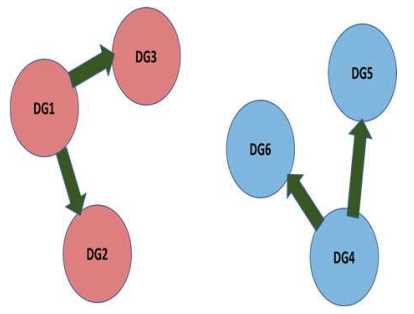

Fig. 17b. Zonal Consensus
Fig. 18a. and Fig. 18b. show the controlled voltages, after a disturbance is applied, of the DGs in each zone using the distributed consensus algorithm. Zone 1 has DGs 1, 2 and 3. Zone 2 has DGs 4, 5 and 6. In both zones the voltages converge to their desired values.

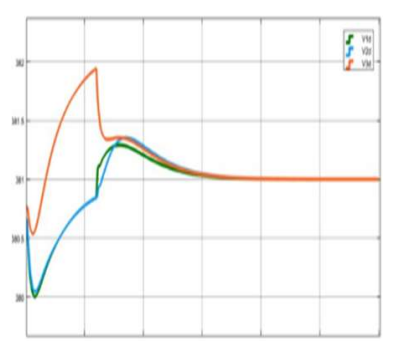

Fig. 18a. Zone 1 Voltages

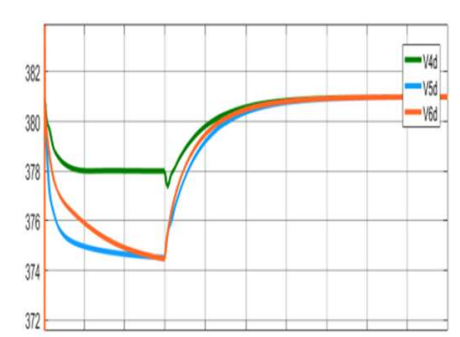

Fig. 18b. Zone 2 Voltages
Fig. 19. shows the voltage of the six units when the global consensus algorithm is utilized. It can be concluded that similar results are obtained using the distributed algorithm, as shown in Fig. 18., an approach that uses less communication.

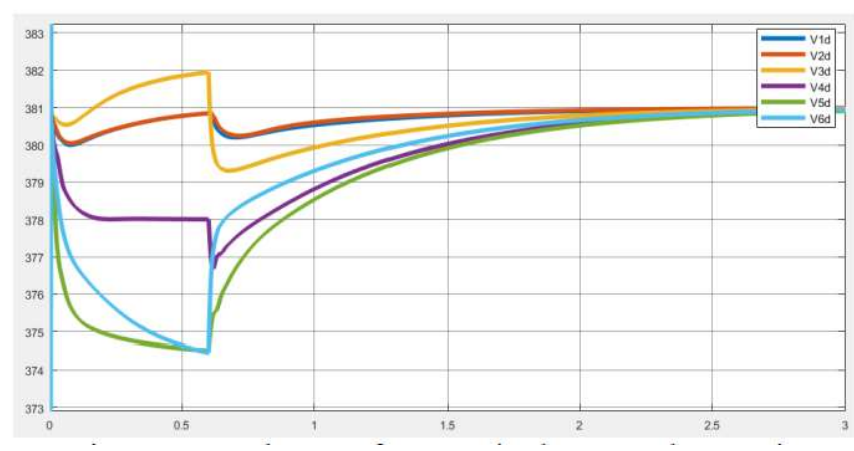

Fig. 19. Voltages of all Six Units using the Global Consensus Algorithm

Obviously, the challenges for voltage and frequency control are many. What is presented here is some work by the author and his colleagues and does not cover a lot of other innovations in the literature.

\section{CONCLUSION}

This paper describes some of the challenges that face the operation of future electric power systems. These systems are becoming more flexible and agile. Their physical structures and connections are continuously changing as microgrids, electric vehicles, and other generation and storage devices are connected/disconnected from the grid, which result in new challenges for the operation, management, and control of the systems of the future that incorporate active participation of the consumers, and high penetration of intermittent nature renewable resources such as wind and solar.

Additionally, numerous challenges are faced by future power systems and they are due to factors that incorporate advances in technology, economics, but also social, policy and environment factors. In this sense, this paper aimed to present some of the following challenges:

- Economics, Deregulation, Policy, Environment

- Multiple Infrastructures

- Electric Transportation

- Communication, Internet, Information

- Computation

- Data Analytics

- Cyber Security

- Operation

- Renewable Resources

○ Dispatch,

- Intermittent Resources

- Network Constraints

- Units Ramp Up/Down: Duck Curve

- Control/Automation, Resiliency

- Power Electronics, Sensors

- Low Inertia, two-way power flow, switching

- Frequency/Voltage Control

The paper does not claim to be a complete presentation of the challenges facing flexible power systems, since these challenges are numerous and relate to a multitude of players and technologies. However, it should draw attention to this important and timely topic and help the reader understand the 
nature of multidisciplinary aspects of this exciting field of research.

\section{ACKNOWLEDGMENT}

The author would like to acknowledge the work of his students and colleagues that have been cited in this paper.

\section{REFERENCES}

[1] https://en.wikipedia.org/wiki/National_Academy_of_Engineering\#Gre atest Engineering Achievements of the 20th Century

[2] https://www.eia.gov/electricity/annual/

[3] https://solar-power-now.com/cost-of-solar/

[4] https://www.woodmac.com/news/feature/the-united-states-surpasses2-million-solar-installations/

[5] https://theconversation.com/whats-behind-15-000-electricity-bills-intexas- 155822

[6] Abduladim Salem, "Internet of Things in Smart Grids," MS Project, West Virginia University, Dec 2015

[7] M.E. Peck, D. Wagman, "Energy Trading for Fun and Profit: Buy your neighbor's rooftop solar power or sell your own-solar-energy-tradingfor-fun-and-profit — it'll all be on a blockchain," IEEE Spectrum, Oct 2017. https://doi.org/10.1109/MSPEC.2017.80488242

[8] https://spectrum.iee.org/computing/networks/blockchains-will-allowrooftophttps://seekingalpha.com/article/4262588-californias-mid-daysolar-power-glut-become-obvious

[9] https://ics.sans.org/media/E-ISAC_SANS_Ukraine_DUC_5.pdf

[10] https://www.latimes.com/projects/la-fi-electricity-solar/

[11] http://www.caiso.com/TodaysOutlook/Pages/index.html

[12] F. Doost Mohammadi, H.K. Vanashi, A. Feliachi, "State Space Modeling, Analysis and Distributed Secondary Frequency Control of Isolated Microgrids," IEEE Transactions on Energy Conversion, Vol. 33, No. 1, pp. 155-165, March 2018. http://doi.org/10.1109/TEC.2017.2757012

[13] F. Doost Mohammadi, H. K. Vanashi, A. Dehghan Banadaki, A. Feliachi, "A novel cooperative distributed secondary controller for VSI and PQ inverters of AC microgrids," Heliyon, Elsevier Ltd., Vol. 5, Issue 6, pp. 1-14, June 2019. https://doi.org/10.1016/j.heliyon.2019.e01823

[14] A.H. Shahirina, A. Hajizadeh, D.C. Yu, A. Feliachi, "Control of a Hybrid Wind Turbine/Battery Energy Storage Power Generation System Considering Statistical Wind Characteristics," Journal of Renewable and Sustainable Energy, Vol. 4, Issue 5, 17 pages, 2012. https://doi.org/10.1063/1.4751472

[15] M.J. Ghorbani, M.A. Choudhry, A. Feliachi, "A Multi-Agent Design for Power Distribution Systems Automation," IEEE Transactions on Smart Grids, pp. 329-339, Vol. 7, No. 1, Jan. 2016. https://doi.org/10.1109/TSG.2015.2453884

[16] A. Hajizadeh, A. Feliachi, M.A. Golkar, "Intelligent Power Management of a Hybrid Fuel Cell/Energy Storage Distributed Generator," Chapter 8, pp. 265-285, Smart Power Grids 2011, Springer Verlag, Feb 2012. https://doi.org/10.1007/978-3-642-21578-0_8

[17] A. Feliachi, R. Belkacemi, "Intelligent Multi-Agent System for Smart Grid Power Management," Chapter 16, pp. 515-542, Smart Power Grids 2011, Springer Verlag, Feb 2012. https://doi.org/10.1007/978-3-64221578-0 16
[18] https://www.cleanenergyreviews.info/blog/2014/5/4/how-solar-works

[19] A. Bidram, A. Davoudi, F.K. Lewis, SS Ge, "Distributed adaptive voltage control of inverter-based microgrids," IEEE Transactions on Energy Conversion, 2014. https://doi.org/ 10.1109/TEC.2014.2359934

[20] A. Dehghan Banadaki, A. Feliachi, V.K. Kulathumani, "Fully Distributed Secondary Voltage Control in Inverter-Based Microgrids," IEEE PES T\&D Conference \& Exposition 2018, April 16-19, 2018, Denver, CO. https://doi.org/ 10.1109/TDC.2018.8440329

\section{BIOGRAPHY}

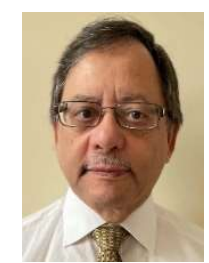

Ali Feliachi received the Diplôme d'Ingénieur en Electrotechnique from the Ecole Nationale Polytechnique of Algiers, Algeria, in 1976, and the MS and Ph.D. degrees in Electrical Engineering from the Georgia Institute of Technology, Atlanta, GA in 1979 and 1983 respectively. He has taught at the Ecole Supérieure de Chimie of the University of Algiers, at Lycée Ourida Meddad in El-Harrach, Algeria, and worked for SONELGAZ in 1976. At Georgia Tech, he was employed as a Graduate Teaching and Research Assistant, then a Postdoc after graduation. He worked, as a consultant, for Georgia Power Company before joining the Lane Department of Computer Science and Electrical Engineering at West Virginia University in 1984 where he is currently a Full Professor and the Director of the Advanced Power \& Electricity Research Center (APERC). He also held the Electric Power Systems Endowed Chair Position for 15 years until 2017.

His research interests are modeling, control and simulation of smart grids and electric power systems. His work has been funded by electric utilities (Allegheny Power, Duquesne Light), and US DoE, US DoD, NSF, and EPRI (Electric Power Research Institute). He has published about 300 journal and conference articles in his field of expertise.

Dr. Feliachi is a Life Senior Member of IEEE, and a member of the honorary societies $\mathrm{Pi} \mathrm{Mu}$ Epsilon (Math), Eta Kappa Nu (Electrical Engineering), and Sigma Xi (Research). He received the ASEE (American Society for Engineering Education) North Central Section Dow Outstanding Young Faculty Award in 1987, the following awards from the College of Engineering at West Virginia University: Leadership Award in 1989, Outstanding Researcher Award in 1991, 2004 and 2005, Researcher of the Year in 2005, Outstanding Graduate Teacher Award in 1991. In 1994 he received the Claude Benedum Distinguished Scholar Award for the Sciences and Technology from West Virginia University. 